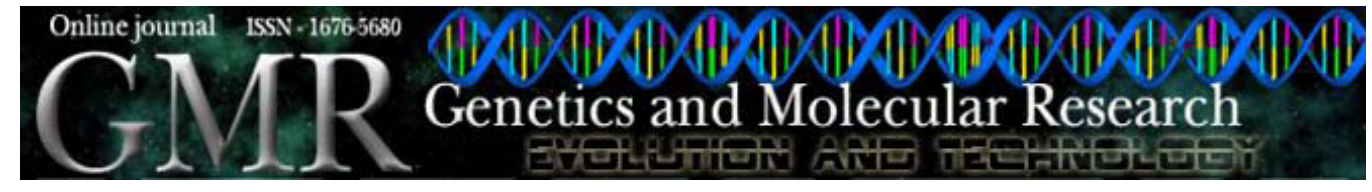

\title{
AFLP markers for identification of Swertia species (Gentianaceae)
}

\author{
A. Misra ${ }^{1}$, A.K. Shasany ${ }^{1}$, A.K. Shukla ${ }^{1}$ M.P. Darokar ${ }^{1}$, S.C. Singh ${ }^{1}$, \\ V. Sundaresan ${ }^{2}$, J. Singh ${ }^{1}$, G.D. Bagchi ${ }^{1}$, S.P. Jain ${ }^{1}$, D. Saikia ${ }^{1}$ and \\ S.P.S. Khanuja ${ }^{1}$ \\ ${ }^{1}$ Central Institute of Medicinal and Aromatic Plants (CSIR), \\ P.O. CIMAP, Lucknow, India \\ ${ }^{2}$ CIMAP Resource Centre (CSIR), P.O. Dairy Farm, Nagla, \\ Pantnagar, Uttarakhand, India \\ The present address of S.P.S. Khanuja is C41-42, \\ Double Storey, Ramesh Nagar, New Delhi, India \\ Corresponding author: A.K. Shasany \\ E-mail: akshasany@yahoo.com
}

Genet. Mol. Res. 9 (3): 1535-1544 (2010)

Received March 11, 2010

Accepted April 20, 2010

Published August 10, 2010

DOI 10.4238/vol9-3gmr785

\begin{abstract}
The genus Swertia is well known for its medicinal properties, as described in the Indian pharmacopoeia. Different members of this genus, although somewhat similar in morphology, differ widely in their pharmacological and therapeutic properties. The most important species of this genus, with maximal therapeutic properties, is $S$. chirayita, which is often adulterated with other lesspotent Swertia spp. There is an existing demand in the herbal drug industry for an authentication system for Swertia spp, in order to enable their commercial use as genuine phytoceuticals. To this end, we used amplified fragment length polymorphism (AFLP) to produce DNA fingerprints for six Swertia species. Nineteen accessions (2 of $S$.
\end{abstract}


chirayita, 3 of $S$. angustifolia, 2 of S. bimaculata, 5 of S. ciliata, 5 of $S$. cordata, and 2 of $S$. alata) were used in the study, which employed 64 AFLP selective primer pairs. Only 46 selective primer pairs were found to be useful for all the accessions. A total of 5312 fragments were produced by these 46 primer pairs. Species-specific markers were identified for all six Swertia species (131 for S. chirayita, 19 for $S$. angustifolia, 181 for S. bimaculata, 47 for S. ciliata, 94 for S. cordata, and 272 for S. alata). These AFLP fingerprints of the Swertia species could be used to authenticate drugs made with Swertia spp and to resolve adulteration-related problems faced by the commercial users of these herbs.

Key words: Adulteration; DNA fingerprinting; Crude drug

\section{INTRODUCTION}

The genus Swertia (family Gentianaceae), founded by Linnaeus in 1753 in honor of Emanuele Sweert, an eminent Dutch gardener, comprises about 170 known species that are mainly native to temperate regions of the northern hemisphere (Brahmachari et al., 2004). About 40 species of Swertia are found in India, mainly at high altitude (1200-3000 m) in the temperate Himalayan region ranging from Kashmir to Bhutan, and also in the Khasia and Western Ghats hills (Chopra et al., 1956; Anonymous, 1982; Scartezzini and Speroni, 2000). Although plants belonging to various Swertia species have been described in different traditional medicine systems for use as crude drugs for the treatment of various ailments, Swertia chirayita occupies the most prominent position as regards its medicinal and therapeutic capabilities. It is traditionally used as a bitter tonic in stimulating appetite, as a febrifuge and for treating asthma and liver disorders (Brahmachari et al., 2004). Its medicinal potential is vividly described in various traditional medicine systems such as Ayurveda and Unani and in the American and British pharmacopoeias. The herb is in high demand as evident from its use in various commercially available popular herbal preparations such as Ayush-64, Diabecon, Mensturyl syrup, and Melicon V ointment (Joshi and Dhawan, 2005). However, this high demand of the drug has raised other concerns as well. Most of the herbal industries collect it from the wild, whereby the natural population of the plant in the wild is diminishing continuously, making it an endangered species (IUCN data). This in turn has created another problem, i.e., adulteration of the authentic drug with its less effective and often harmful substitutes. Species of other genera (Andrographis paniculata, Exacum tetragonum, E. pedunculatum, Slevolgia orientalis) as well as the genus Swertia (S. alata, S. angustifolia, S. bimaculata, S. ciliata, S. densifolia, S. elegans, S. lawii, S. minor, S. paniculata, S. multiflora, $S$. cordata) are used as adulterants for $S$. chirayita (Anonymous, 1982). Most of these adulterants/substitutes have inferior biological activity as compared to $S$. chirayita. Although $S$. chirayita has been morphologically and chemotypically differentiated from other species of Swertia (Bhatia et al., 2003), it is not possible to use these markers when the herb is present in the crude drug form. This problem could not be resolved by the isozyme markers that have been used to differentiate the Swertia species (Verma and Kumar, 2001). It is, therefore, an absolute necessity for the herbal drug industry to have DNA markers for 
various Swertia species so as to differentiate and authenticate the herbal material when it is present in the form of a crude drug. Although molecular profiling of the "Chirayat" complex has been recently reported using inter-simple sequence repeat (ISSR) markers, the study generated very few polymorphic bands (Tamhankar et al., 2009). Hence, the present study was undertaken to generate amplified fragment length polymorphism (AFLP)-based DNA markers for 6 Swertia species (S. chirayita, S. angustifolia, S. bimaculata, S. ciliata, S. cordata, and $S$. alata) that are most commonly used in the herbal trade. Although previous attempts have been made to analyze the intra- and interspecific genetic diversity of Swertia species at the molecular level using ISSR DNA markers (Joshi and Dhawan, 2007a), this study is the first attempt to generate AFLP-based DNA markers for 6 prominent species of the genus Swertia that are commonly used in the herbal drug trade.

\section{MATERIAL AND METHODS}

\section{Plant material}

The plant material used in this study was collected from the Himalayan region in the Indian States of West Bengal, Sikkim, Uttarakhand, and Himachal Pradesh, and the herbarium was submitted to the National Gene Bank for Medicinal and Aromatic Plants at CIMAP, Lucknow (Table 1). Leaf samples from the selected plants were used for DNA isolation. The samples consisted of two accessions each of $S$. chirayita, $S$. bimaculata and $S$. alata, three accessions of $S$. angustifolia and five accessions each of S. ciliata and $S$. cordata.

\begin{tabular}{|c|c|c|}
\hline Sample No. & Name & Place of collection \\
\hline 1 & S. chirayita 1 & Sikkim \\
\hline 2 & S. chirayita 2 & Sukhia pokhari, Darjeeling, West Bengal \\
\hline 3 & S. angustifolia 1 & Tehri Garhwal, Uttarakhand \\
\hline 4 & S. angustifolia 2 & Kaddukhal, Chamba, Uttarakhand \\
\hline 5 & S. angustifolia 3 & Sukhia pokhari, Darjeeling, West Bengal \\
\hline 6 & S. bimaculata 1 & Darjeeling, West Bengal \\
\hline 7 & S. bimaculata 2 & Darjeeling, West Bengal \\
\hline 8 & S. ciliata 1 & Kandar, Suki, Uttarkashi, Uttarakhand \\
\hline s9 & S. ciliata 2 & Raithal, Bhatwari, Uttarkashi, Uttarakhand \\
\hline 10 & S. ciliata 3 & Kandar, Suki, Uttarkashi, Uttarakhand \\
\hline 11 & S. ciliata 4 & Darjeeling, West Bengal \\
\hline 12 & S. ciliata 5 & Manibhanjan, Darjeeling, West Bengal \\
\hline 13 & S. cordata 1 & Raithal, Bhatwari, Uttarkashi, Uttarakhand \\
\hline 14 & S. cordata 2 & Chamba, Uttarakhand \\
\hline 15 & S. cordata 3 & Gangotri, Uttarakhand \\
\hline 16 & S. cordata 4 & Kumaon Himalaya, Uttarakhand \\
\hline 17 & S. cordata 5 & Manali, Himachal Pradesh \\
\hline 18 & S. alata 1 & Chamba, Uttarakhand \\
\hline 19 & S. alata 2 & Darjeeling, West Bengal \\
\hline
\end{tabular}




\section{DNA isolation}

DNA was isolated from the plant leaf samples using the protocol described by Khanuja et al. (1999), and its quality and quantity were analyzed using agarose gel electrophoresis and an ND-1000 spectrophotometer (NanoDropTechnologies, USA).

\section{AFLP}

For AFLP analysis, DNA was cleaved using the restriction endonucleases EcoRI and Tru9I (an isoschizomer of MseI), and double-stranded adapters were ligated to the ends of DNA fragments, generating a template for subsequent polymerase chain reaction (PCR) amplification (preselective followed by selective). Restriction and ligation reactions were carried out simultaneously in a single reaction (Vos et al., 1995). To carry out the reaction, an enzyme master mix for 10 reactions was prepared containing $1 \mu \mathrm{L}$ 10X T4 DNA ligase buffer, $1 \mu \mathrm{L} 0.5$ $\mathrm{M} \mathrm{NaCl}, 0.5 \mu \mathrm{L} 1 \mathrm{mg} / \mathrm{mL}$ BSA, $1 \mu \mathrm{L}$ Tru9I $(10 \mathrm{U} / \mu \mathrm{L}), 4.25 \mu \mathrm{L}$ EcoRI $(12 \mathrm{U} / \mu \mathrm{L}), 0.5 \mu \mathrm{L}$ T4 DNA ligase $(20 \mathrm{U} / \mu \mathrm{L}$, high concentration) and $1.75 \mu \mathrm{L}$ water. The restriction ligation reaction mix consisted of $300 \mathrm{ng}$ DNA $(5.5 \mu \mathrm{L}), 1 \mu \mathrm{L} 10 \mathrm{X}$ T4 DNA ligase buffer, $1 \mu \mathrm{L} 0.5 \mathrm{M} \mathrm{NaCl}$, $0.5 \mu \mathrm{L} 1 \mathrm{mg} / \mathrm{mL}$ BSA, $1 \mu \mathrm{L}$ MseI adapter (Applied Biosystems, USA), $1 \mu \mathrm{L}$ EcoRI adapters (Applied Biosystems) and $1 \mu \mathrm{L}$ enzyme master, as described above. The reaction was then incubated overnight at room temperature and subsequently diluted 20 -fold with $\mathrm{T}_{10} \mathrm{E}_{0.1}$ buffer. The ligated adaptors served as primer binding sites for low-level selection in the preselective amplification of restriction fragments. The MseI complementary primer had a 3'-C and the EcoRI complementary primer had a 3'-A. Only the genomic fragments having an adapter on each end amplified exponentially during PCR. The preselective amplification mix was prepared by adding $4 \mu \mathrm{L}$ of 20 -fold diluted DNA from the restriction ligation reaction, 0.5 $\mu \mathrm{L}$ AFLP preselective primer (EcoRI, Applied Biosystems), $0.5 \mu \mathrm{L}$ AFLP preselective primer (MseI, Applied Biosystems) and $15 \mu \mathrm{L}$ AFLP core mix. The preselective amplification was carried out in a thermal cycler programmed as follows: $72^{\circ} \mathrm{C}$ for $2 \mathrm{~min} ; 20$ cycles of $94^{\circ} \mathrm{C}$ for $20 \mathrm{~s}, 56^{\circ} \mathrm{C}$ for $30 \mathrm{~s}$ and $72^{\circ} \mathrm{C}$ for $2 \mathrm{~min} ; 60^{\circ} \mathrm{C}$ for $30 \mathrm{~min}$, and $4^{\circ} \mathrm{C}$ for infinity.

The preamplified DNA was diluted 20 -fold with $\mathrm{T}_{10} \mathrm{E}_{0.1}$ buffer, and selective amplifications were carried out using different MseI and EcoRI primer combinations (Applied Biosystems). Primers chosen for the amplification were from 16 available AFLP selective primers ( 8 fluorescently tagged EcoRI and 8 untagged $M s e$ I primers). The EcoRI primers contained 3 selective nucleotides with the sequence 5' [Dye-Primer-Axx]-3', while the MseI primers had the 3 selective nucleotides starting with C, i.e., 5'-[Primer-Cxx]-3'. Selective amplification of each sample was done with all $64(8 \times 8)$-primer combinations (MseI/EcoRI) using multiplex-PCR. For selective amplification, the reactions were set up as follows: $3 \mu \mathrm{L}$ of 20 -fold diluted preselective amplification product, $15 \mu \mathrm{L}$ AFLP core mix, $1 \mu \mathrm{L}$ MseI primer 5'-[Primer-Cxx]-3', and 1.5 $\mu \mathrm{L}$ EcoRI primers 5'-[Dye-PrimerAxx $]-3^{\prime}(0.5 \mu \mathrm{L} 3$ EcoRI primers each were pooled here). Selective amplification was carried out in a thermal cycler programmed as follows: $94^{\circ} \mathrm{C}$ for $2 \mathrm{~min} ; 10$ cycles of $94^{\circ} \mathrm{C}$ for $20 \mathrm{~s}, 66^{\circ} \mathrm{C}\left(-1^{\circ} \mathrm{C} /\right.$ cycle $)$ for $30 \mathrm{~s}$, and $72^{\circ} \mathrm{C}$ for $2 \mathrm{~min} ; 20$ cycles of $94^{\circ} \mathrm{C}$ for $20 \mathrm{~s}, 56^{\circ} \mathrm{C}$ for $30 \mathrm{~s}$, and $72^{\circ} \mathrm{C}$ for $2 \mathrm{~min} ; 60^{\circ} \mathrm{C}$ for $30 \mathrm{~min}$, and $4^{\circ} \mathrm{C}$ for infinity. The samples were loaded onto a 5\% (29:1) polyacrylamide gel on an ABI Prism 377 DNA Sequencer (Applied Biosystems, USA). For gel electrophoresis, $3 \mu \mathrm{L}$ of the selective amplification reaction 
product was mixed with $4 \mu \mathrm{L}$ loading buffer [ROX500 size standard (10\%), blue dextran $(10 \%)$, and deionized formamide (80\%)], and $1.5 \mu \mathrm{L}$ of this mix was finally loaded on the gel. The AFLP amplification modules and the guidelines supplied by Applied Biosystems, USA, were used for setting up the reactions as described above.

\section{Data analysis}

Fragment analysis was carried out for bands in the range of 35-400 bp. For diversity analysis, bands were scored as present (1) or absent (0) to form a raw data matrix. A square symmetric matrix of similarity was then obtained with Jaccard's similarity coefficient (Jaccard, 1908) using the SPSS v 7.5 software. The average similarity matrix was used to generate a tree for cluster analyses by UPGMA (unweighted pair group method with arithmetic mean) method using NTSys v 2.1.

\section{RESULTS AND DISCUSSION}

In the AFLP analysis, of the 64 primer pairs, only 46 responded positively and generated discrete bands with all the plant samples. Of a total of 5312 bands, 8 were monomorphic and 5304 were polymorphic. A polymorphism of $99 \%$ was detected among the species. A total of 743 bands were found to be unique for various Swertia species. In this analysis, species-specific markers were identified for the 6 Swertia species (131 for S. chirayita, 19 for S. angustifolia, 181 for S. bimaculata, 47 for S. ciliata, 94 for S. cordata, and 272 for S. alata) (Table 2). The cluster diagram obtained after analysis indicated 6 major groups, each representing one of the 6 different species of Swertia used in the study, as expected (Figure 1). In the first group, two accessions of S. chirayita clustered together, showing $46 \%$ similarity. The second group consisted of the three accessions of $S$. angustifolia grouping together with $20 \%$ similarity within the cluster. Similarly, five accessions of $S$. ciliata, showing $40 \%$ similarity, two accessions of $S$. alata showing $58 \%$ similarity and two accessions of $S$. bimaculata showing $62 \%$ similarity, clustered into the third, fourth and fifth groups, respectively. The last group (sixth) consisted of five accessions of $S$. cordata showing $47 \%$ similarity among the accessions. The results obtained in the present study clearly showed that $S$. cordata and S. angustifolia did not cluster together as found in a previous ISSR-based study carried out by Tamhankar et al. (2009).

In a previous study using ISSR markers, Joshi and Dhawan (2007a) found 98.7\% polymorphism among 19 genotypes of Swertia species (13 of S. chirayita and 2 each of S. cordata, $S$. paniculata and $S$. purpurascens). They also found through ISSR analyses that the clonal/ genetic fidelity of $S$. chirayita is maintained in micropropagated plantlets generated using an in vitro multiplication method (Joshi and Dhawan, 2007b). The genus Swertia has been described in the literature as being highly polyphyletic (von Hagen and Kadereit, 2001). Considering the range of different niches occupied by the plant, there is a possibility that many ecotypes and/ or chemotypes of even a single species such as $S$. chirayita exist in nature (Joshi and Dhawan, 2005). When making use of the plant for commercial purposes as an herbal drug, it is very important to identify the correct chemotype having the maximal content of the therapeutically significant secondary metabolites. This identification requires the use of molecular markers that are unique to the relevant plant and that are stable under different conditions (plant age, environment, etc.). DNA markers are best suited to serve this purpose. 
A. Misra et al.

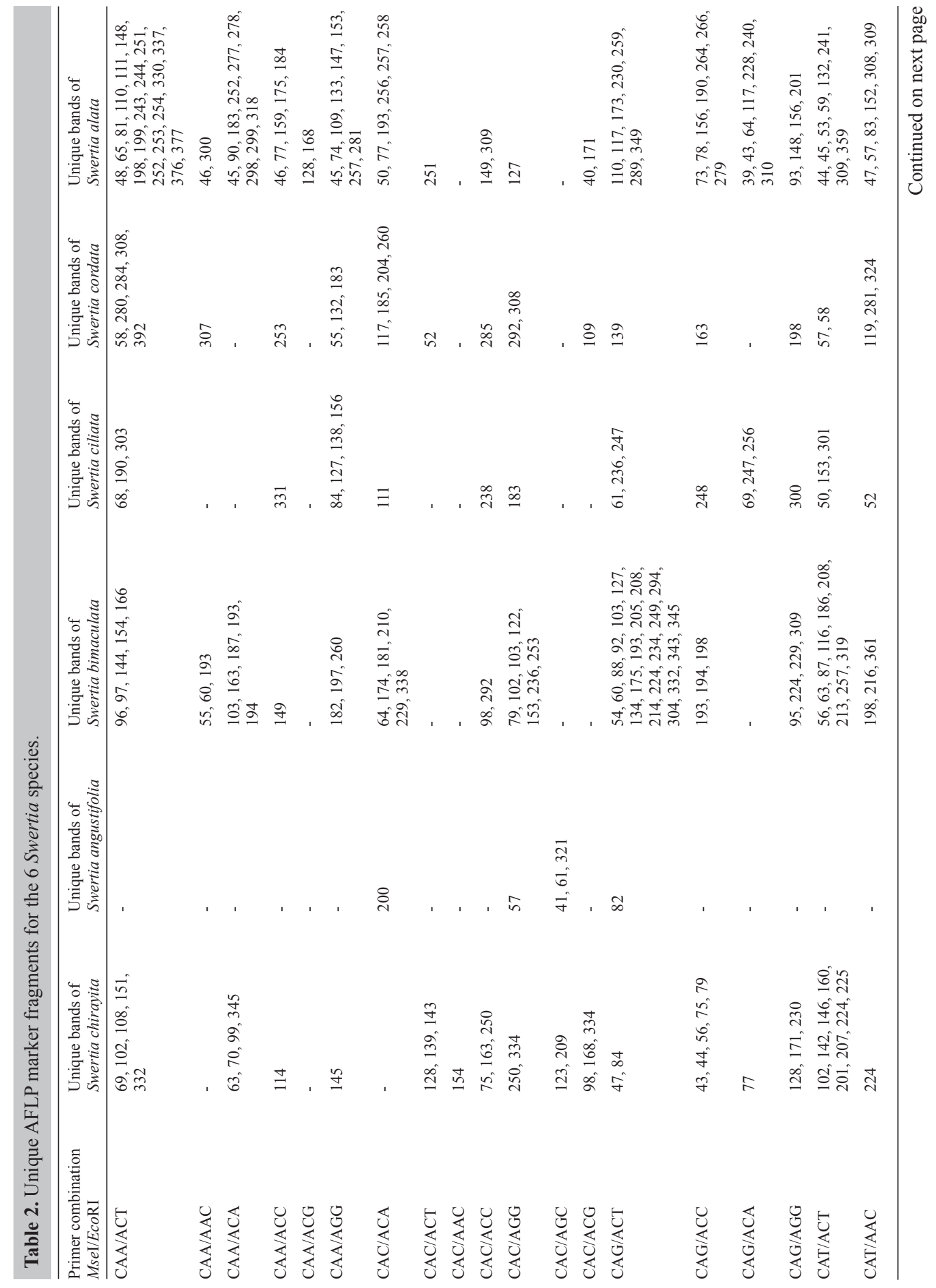

Genetics and Molecular Research 9 (3): 1535-1544 (2010) 


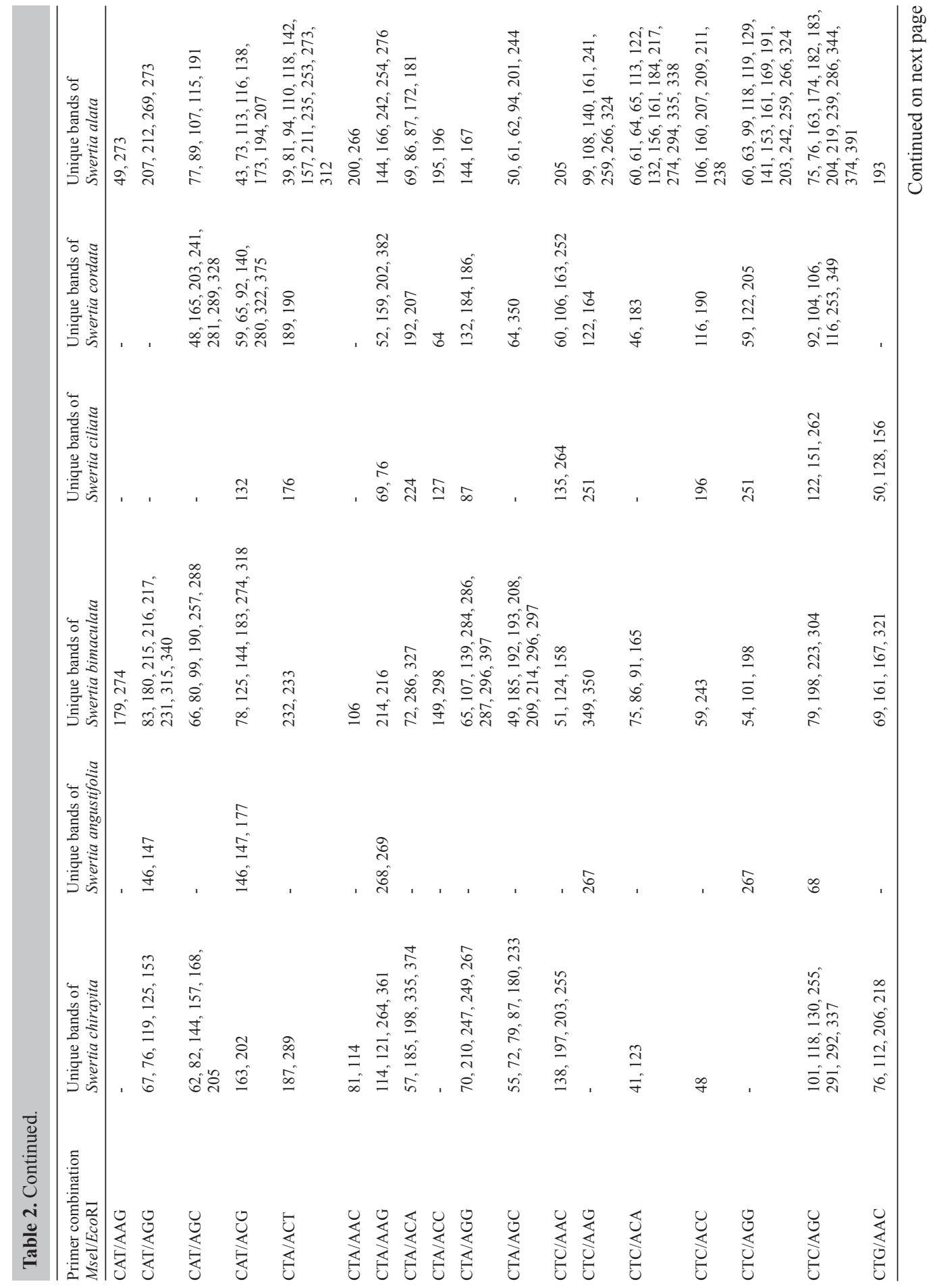


A. Misra et al.

1542

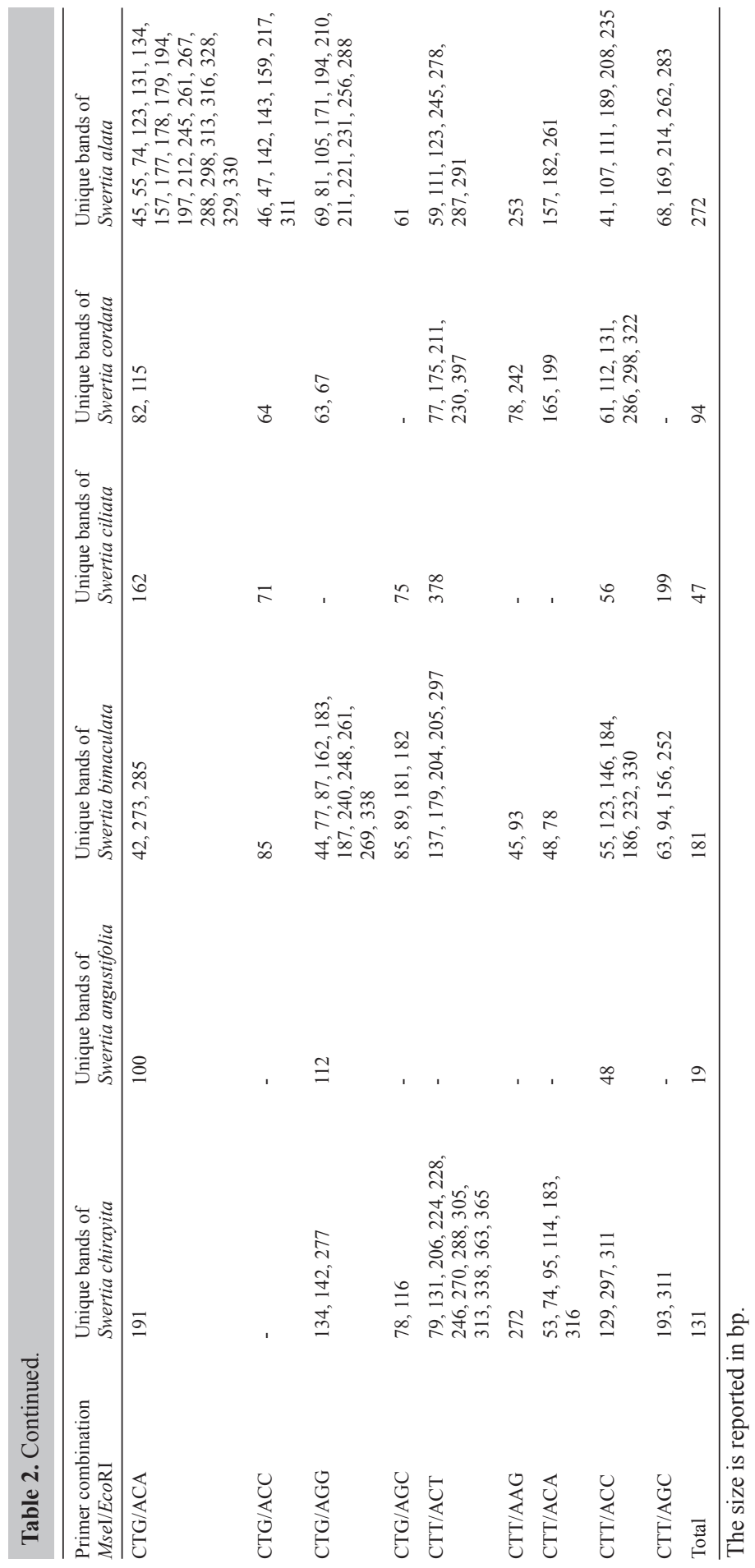




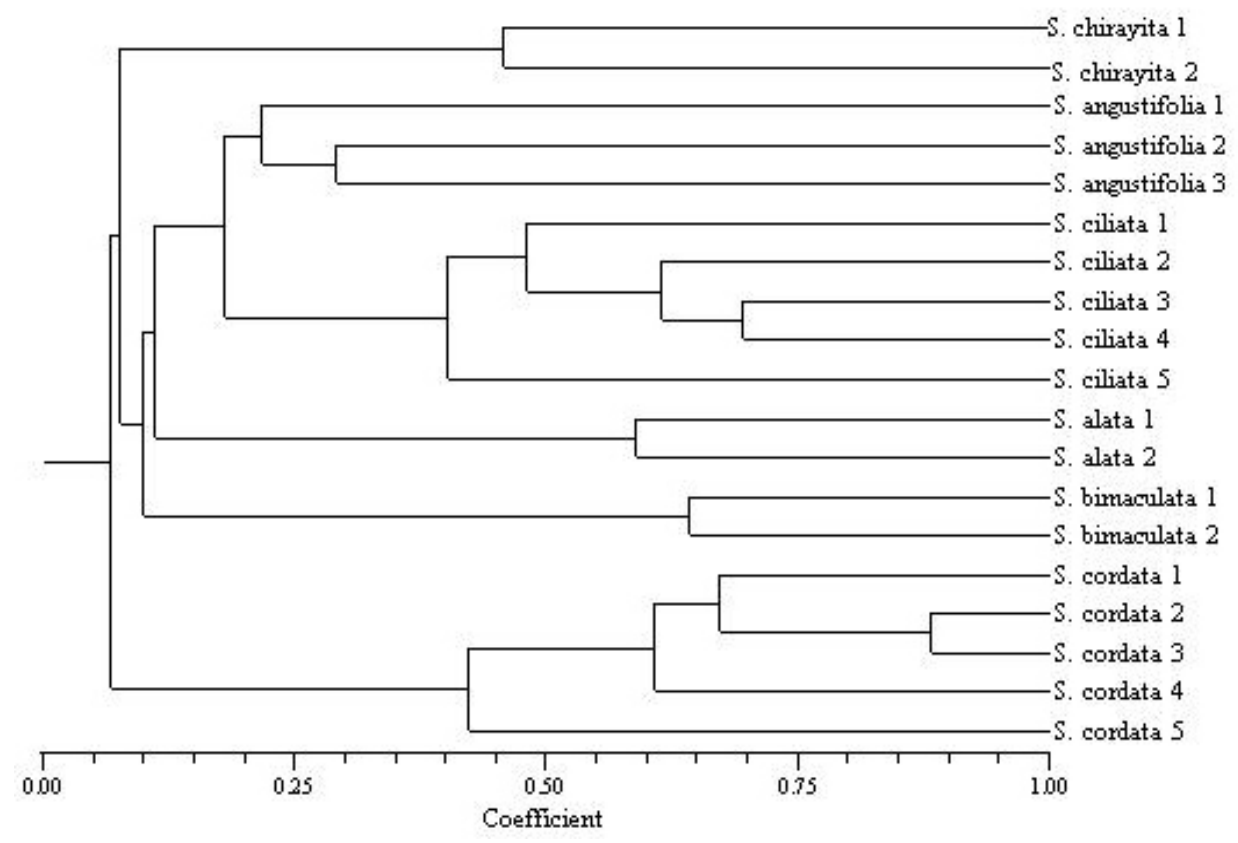

Figure 1. Cluster diagram showing relationship among 6 Swertia species.

The DNA molecular markers (unique bands) for Swertia species generated in the present study (Table 2) would provide a useful reference tool to identify the herbal material when present in the form of crude drug and would circumvent the problems associated with morphological, chemotypic and isozyme markers. The frequency of the occurrence of these unique bands in the analysis of the DNA isolated from the crude drug preparation could be used in an assay for the presence of a specific species population. In the past, AFLP and other DNA markers have also been used to resolve complex polyherbal mixtures and to identify specific species present in them. In an earlier study, we used the same approach to resolve the "Safed Musli" complex and detect the presence of adulterants in crude drug preparations of the herb, which is commonly known to contain Chlorophytum species along with Asparagus adscendens (Misra et al., 2007). Recently, species-specific SCAR markers have been used to tag specific Phyllanthus species that are prevalent in the herbal drug trade (Jain et al., 2008). AFLP, in particular, has been the method of choice for discriminating closely related species and authentication of herbs, as demonstrated for Plectranthus genus in an earlier study (Passinho-Soares et al., 2006). In the present study, too, a well-defined grouping pattern was obtained for all 6 Swertia species analyzed. The significance of this study stems from the fact that it provides an authentication tool to detect adulterants in the crude drug preparations of Swertia and to maintain the quality standards in the herbal drug industry.

\section{ACKNOWLEDGMENTS}

Research supported by ICMR and CSIR, India. The authors also acknowledge the 
help of Dr. Anil K. Gupta, Curator, National Gene Bank for Medicinal and Aromatic Plants, CIMAP, Lucknow.

\section{REFERENCES}

Anonymous (1982). The Wealth of India: Raw Materials. Vol. X. Publication and Information Directorate. CSIR, New Delhi, 78-81.

Bhatia A, Karan M and Vasisht K (2003). Morphological and chemotypic comparison of certain Indian species of Swertia. J. Med. Aromat. Plant Sci. 25: 336-343.

Brahmachari G, Mondal S, Gangopadhyay A, Gorai D, et al. (2004). Swertia (Gentianaceae): chemical and pharmacological aspects. Chem. Biodivers. 1: 1627-1651.

Chopra RN, Nayar SL and Chopra IC (1956). Glossary of Indian Medicinal Plants. CSIR, New Delhi, 237.

Jaccard P (1908). Nouvelles recherches sur la distribution florale. Bull. Soc. Vaudoise Sci. Naturelles 44: 223-270.

Jain N, Shasany AK, Singh S, Khanuja SPS, et al. (2008). SCAR markers for correct identification of Phyllanthus amarus, $P$. fraternus, $P$. debilis and P. urinaria used in scientific investigations and dry leaf bulk herb trade. Planta Med. 74: 296-301.

Joshi P and Dhawan V (2005). Swertia chirayita - an overview. Curr. Sci. 89: 635-640.

Joshi P and Dhawan V (2007a). Analysis of genetic diversity among Swertia chirayita genotypes. Biol. Plant. 51: 764-768.

Joshi P and Dhawan V (2007b). Assessment of genetic fidelity of micropropagated Swertia chirayita plantlets by ISSR marker assay. Biol. Plant. 51: 22-26.

Khanuja SPS, Shasany AK, Darokar MP and Kumar S (1999). Rapid isolation of PCR amplifiable DNA from the dry and fresh sample of plants producing large amounts of secondary metabolites and essential oils by modified CTAB procedure. Plant Mol. Biol. Rep. 17: 74.

Misra A, Shasany AK, Shukla AK, Sundaresan V, et al. (2007). AFLP-based detection of adulterants in crude drug preparations of the 'Safed Musli' complex. Nat. Prod. Comm. 2: 93-97.

Passinho-Soares H, Felix D, Kaplan MA, Margis-Pinheiro M, et al. (2006). Authentication of medicinal plant botanical identity by amplified fragmented length polymorphism dominant DNA marker: inferences from the Plectranthus genus. Planta Med. 72: 929-931.

Scartezzini P and Speroni E (2000). Review on some plants of Indian traditional medicine with antioxidant activity. J. Ethnopharmacol. 71: 23-43.

Tamhankar S, Ghate V, Raut A and Rajput B (2009). Molecular profiling of "Chirayat" complex using inter simple sequence repeat (ISSR) markers. Planta Med. 75: 1266-1270.

Verma NK and Kumar A (2001). Isozyme polymorphism and genetic diversity among Swertia species-endangered medicinal plants of Himalayas. Ind. J. Plant Genet. Res. 14: 74-77.

von Hagen KB and Kadereit JW (2001). The phylogeny of Gentianella (Gentianaceae) and its colonization of the southern hemisphere as revealed by nuclear and chloroplast DNA sequence variation. Organ. Diver. Evol. 1: 61-79.

Vos P, Hogers R, Bleeker M, Reijans M, et al. (1995). AFLP: a new technique for DNA fingerprinting. Nucleic Acids Res. 23: 4407-4414. 